\title{
The anti-inflammatory sesquiterpene lactone parthenolide suppresses CD95-mediated activation-induced-cell-death in T-cells
}

\author{
M Li-Weber*, ${ }^{\star 1}$ M Giaisi ${ }^{1}$, S Baumann ${ }^{1}$, MK Treiber $^{1}$ and \\ PH Krammer ${ }^{1}$ \\ 1 Tumorimmunology Program, German Cancer Research Center (DKFZ), \\ D-69120 Heidelberg, Germany \\ * Corresponding author: Dr M Li-Weber, Tumor Immunology Program C0300, \\ German Cancer Research Center (DKFZ), Im Neuenheimer Feld 280, 69120 \\ Heidelberg, Germany. Tel: 49 6221 423748; Fax: 496221 411715; \\ E-mail: m.li-weber@dkfz-heidelberg.de
}

Received 7.5.02; revised 28.6.02; accepted 16.7.02

Edited by PA Knight

\begin{abstract}
Apoptosis is a morphologically distinct form of cell death involved in many physiological and pathological processes. The death receptor CD95 (APO-1/Fas) and its ligand (L) CD95L are critically involved in activation-induced-cell-death (AICD) of activated T-cells. Here we show that the anti-inflammatory sesquiterpene lactone parthenolide derived from the European traditional herb-medicine feverfew and many Mexican India medicinal plants suppresses expression of the CD95L and CD95 at the mRNA levels, thus, preventing T-cells from AICD. We demonstrate that parthenolide blocks NF- $k$ B binding to the two NF- $\kappa$ binding sites of the CD95L promoter and suppresses promoter activity upon T-cell activation. Aberrant expression of CD95 and, particularly CD95L is dangerous and may lead to severe diseases. Our study indicates that parthenolide supports T-cell survival by downregulating the CD95 system, at least in part, and, therefore, may have therapeutic potential as a new anti-apoptotic substance against AICD in T-cells.

Cell Death and Differentiation (2002) 9, 1256-1265. doi:10.1038/sj.cdd.4401102
\end{abstract}

Keywords: CD95; APO-1/Fas, apoptosis; T-cells; NF- $\kappa$ B; parthenolide

Abbreviations: TCR, T-cell receptor; AICD, activation-inducedcell-death; SL, sesquiterpene lactone; PMA, phorbol 12-myristate 13-acetate; RT-PCR, reverse transcription-polymerase chain reaction; EMSA, electrophoretic mobility shift assay

\section{Introduction}

Apoptosis is the most common form of eukaryotic cell death and is a process required for the normal development of an organism. CD95L, a type II trans-membrane protein of the tumor necrosis factor (TNF) family, is an important molecule implicated in activation-induced apoptosis of T-lymphocytes, the maintenance of immunologically privileged anatomical sites, and CTL and NK cell-mediated cytotoxicity against a variety of tumor and virus-infected cells. ${ }^{1,2}$ CD95 mediated apoptosis is also known to be a mechanism for maintenance of peripheral tolerance and for termination of an ongoing immune response. ${ }^{2,3}$ However, aberrant expression of CD95L and CD95 is dangerous and leads to severe diseases which have been well documented in the pathogenesis of lymphadenopathy and autoimmunity in human and in animal models. ${ }^{4-9}$ Increased expression of CD95L is also shown to be responsible, at least in part, for the progressive loss of $\mathrm{CD}^{+}{ }^{+}$T-cells in HIV-1-infected individuals. ${ }^{10}$

Expression of CD95L is restricted to a few cell types such as activated T-cells, macrophages, and to cells in tissues of immune privileged sites such as the testis and the eye. CD95L is not present in resting T-cells and is highly expressed upon T-cell activation through the TCR. ${ }^{11}$ In addition, a variety of environmental stress stimuli such as UV irradiation, $\gamma$-irradiation and DNA-damaging agents, can induce CD95L expression. ${ }^{12,13}$ In contrast, CD95 is expressed on various tissues. On peripheral blood T-cells, CD95 expression is low and only increased after T-cell activation. ${ }^{14}$ Binding of CD95L to CD95 results in rapid apoptosis of CD95 bearing cells. Since CD95L expression is a crucial step leading to CD95-mediated apoptosis, many studies have been performed to explore the molecular mechanisms involved in CD95L activation and to identify potential therapeutic targets. Transcription factors such as NF-AT, Egr-1, 2, 3, NF- $\kappa \mathrm{B}, \mathrm{AP}-1$ and SP-1 have been shown to participate in regulation of CD95L expression in T-cells (for a review see ${ }^{15}$ ). Some of the transcription factors such as NF-AT and Egr, have been shown to play an important role in CD95L expression. Targeting NF-AT activity using the immunosuppressive drug Cyclosporin $A$ (CsA) can block CD95L mRNA expression and, consequently, block activation-induced-cell-death (AICD) in Tcells. $^{16}$

Recently, Sesquiterpene lactones (SLs), derived from Mexican India medicinal plants and European feverfew, have raised considerable interest because of their antiinflammatory and complex pharmacological action. ${ }^{17,18}$ SLs containing herbs are frequently used by Mexican Indians for treatment of stomach-ache, infection of the skin and other organs. ${ }^{17,18}$ Feverfew has been used in traditional medicine in the prophylactic treatment of migraine. ${ }^{19}$ Investigation of different SLs revealed that some of the SLs are potent and relatively specific inhibitors of the proinflammatory transcription factor NF- $\kappa \mathrm{B} .^{20-22}$ Normally, NF$\kappa \mathrm{B}$ remains sequestered in an inactive state by cytoplasmic inhibitor-of- $\kappa \mathrm{B}\left(\mathrm{l}_{\kappa} \mathrm{B}\right)$ proteins. Numerous stimuli including cytokines, phorbol esters (e.g. PMA), and T-cell activation 
lead to phosphorylation, ubiquitinylation, and the subsequent degradation of $\mathrm{I} \kappa \mathrm{B}$ proteins. The DNA-binding subunits of $N F-\kappa B$ immigrate into the nucleus and activate expression of numerous target genes that are important for inflammatory responses and the immune response (for review see ${ }^{23}$ ). SLs were shown to specifically inhibit NF- $\kappa \mathrm{B}$ by targeting the $\mathrm{I} \kappa \mathrm{B}$ kinase complex $(\mathrm{IKK} \alpha$ and $\mathrm{IKK} \beta)$ and preventing phosphorylation of $\mathrm{I}_{\kappa} \mathrm{B} .^{20,21}$ More recently, it was also shown that SLs may directly inhibit NF- $\kappa$ B by alkylating p65 at Cysteine 38 which is required for DNA binding. ${ }^{22}$

We have previously identified two NF- $\kappa \mathrm{B}$ regulatory sites in the human CD95L promoter and shown that these two sites are involved in transactivation of the CD95L promoter upon T-cell activation. ${ }^{24} \mathrm{We}$ and others have previously shown that the HIV-1 Tat protein essential for efficient HIV1 gene expression and replication enhances apoptosis via up-regulation of CD95L expression. ${ }^{25,26}$ The two NF- $\kappa \mathrm{B}$ binding sites of the CD95L promoter may, at least in part, respond to HIV-1 Tat. $^{24}$ In addition, the CD95 promoter and CD95 mRNA were also shown to be up-regulated by NF- $\kappa \mathrm{B}$ after stimulation of T-cells by $\mathrm{PMA}$ and ionomycin. ${ }^{27}$ Therefore, NF- $\kappa \mathrm{B}$ may play an important role in regulation of AICD in T-cells. In this study, we asked whether CD95mediated AICD in T-cells can be prevented via targeting $\mathrm{NF}-\kappa \mathrm{B}$ function by SLs. We show here a dose-dependent down-regulation of AICD in T-cells by the anti-inflammatory SL parthenolide. CD95L expression is significantly inhibited by parthenolide at the mRNA and protein levels. Inhibition of CD95 mRNA and protein expression was also observed. Our studies indicate that parthenolide is a potent inhibitor of CD95L gene expression and might be used for development of drugs in prevention of CD95L-mediated apoptosis.

\section{Results}

\section{Parthenolide protects apoptosis in activated Jurkat T-cells}

Jurkat T-cells express both CD95 and CD95L and have been used as a model system for apoptosis studies. ${ }^{16}$ To analyze the effect of parthenolide on T-cell death, a Jurkat T-cell subclone J-27 susceptible to TCR-induced AICD was used for this study. We found that parthenolide significantly downregulated AICD in these cells. $A$ representative result is shown in Figure 1. Activation of J-27 T-cells through TCR by $\alpha \mathrm{CD} 3$ antibody resulted in AICD. In the presence of parthenolide, $\alpha \mathrm{CD} 3$-induced cell death was down-regulated in a dose-dependent manner (Figure 1). Approximate 50$60 \%$ reduction in apoptotic cells was seen in the presence of 2.0-3.0 $\mu \mathrm{M}$ parthenolide (Figure 1). To analyze the toxicity of parthenolide, J-27 cells were cultured with different doses of parthenolide for different time points and the live cells were counted by Trypan blue dye exclusion. No toxicity was seen when the cells were cultured with up to $2.5 \mu \mathrm{M}$ parthenolide for $24 \mathrm{~h}$ (Figure 2A) or longer (data not shown). Slight inhibition of cell proliferation was seen by $5 \mu \mathrm{M}$ parthenolide. Ten $\mu \mathrm{M}$ parthenolide completely blocked cell proliferation and also led to an increase in dead cells (Figure 2A). Correlatively, AICD was largely inhibited by up to $5 \mu \mathrm{M}$ of parthenolide

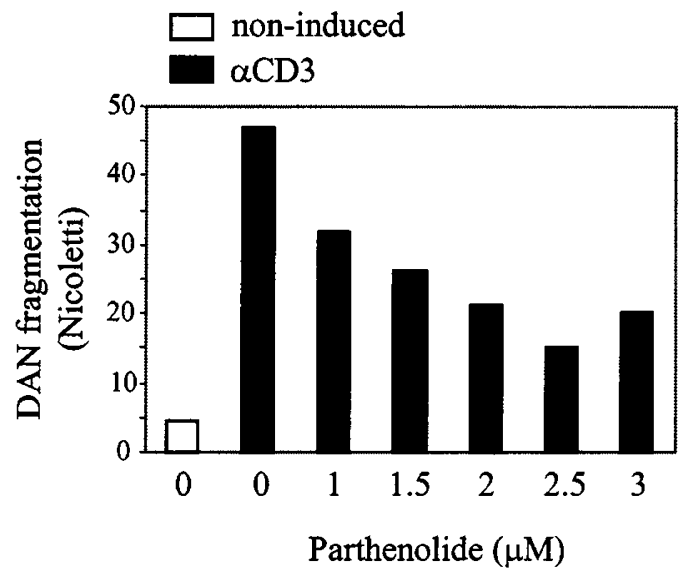

Figure 1 Parthenolide down-regulates AICD in J-27 Jurkat T leukemia cells. $\mathrm{J}-27$ cells were activated via TCR stimulation by $\alpha \mathrm{CD} 3$ antibodies in the absence or presence of different amounts of parthenolide (added $1 \mathrm{~h}$ before activation as indicated) for $24 \mathrm{~h}$. Apoptotic cells were analyzed by FACS for DNA fragmentation

(Figure 2B). Ten $\mu \mathrm{M}$ parthenolide appeared to be toxic and had no inhibitory effect on AICD (Figure 2B). In the presence of the CD95 blocker soluble CD95-Fc or the CD95L blocking antibody NOK1, AICD was largely inhibited demonstrating that CD95 and CD95L represent the main death system involved in AICD in J-27 T-cells (Figure 2C).

\section{Parthenolide inhibits CD95L and CD95 mRNA expression in activated Jurkat T-cells}

Since the CD95 system plays an important role in AICD in Tcells, we next investigated wether parthenolide affects expression of CD95 and CD95L. J-27 cells were stimulated by either PMA/ionomycin or $\alpha \mathrm{CD} 3 / \alpha \mathrm{CD} 28$ in the presence or absence of $5 \mu \mathrm{M}$ parthenolide for different times and total RNA was isolated for RT-PCR analysis. Upon T-cell activation, CD95L mRNA in J-27 cells was rapidly induced and its expression was substantially reduced in the presence of parthenolide (Figure 3A,B). Quantitative analysis by realtime RT-PCR showed an approximate $50 \%$ reduction in CD95L mRNA expression by treatment with $5 \mu \mathrm{M}$ parthenolide (Figure $3 \mathrm{C}$ ). In contrast, the levels of CD95 mRNA were only slightly increased upon activation of the J-27 cells and were only marginally $(15-20 \%)$ affected by parthenolide (Figure $3 A-C)$.

\section{Parthenolide suppresses CD95L and CD95 promoter activity}

To further investigate whether down-regulation of CD95L and CD95 mRNA expression by parthenolide occurred at the transcriptional level, we examined the effect of parthenolide on CD95L and CD95 promoter activity. Luciferase reporter constructs containing up to -860 of the human CD95L and up to -1740 of the human CD95 promoters were used for transient transfection studies. Different doses of parthenolide were added to the cell culture $1 \mathrm{~h}$ before T-cell activation. Activation of $\mathrm{J}-27$ cells with $\alpha \mathrm{CD} 3$ or with PMA/ionomycin led 
$\mathbf{A}$

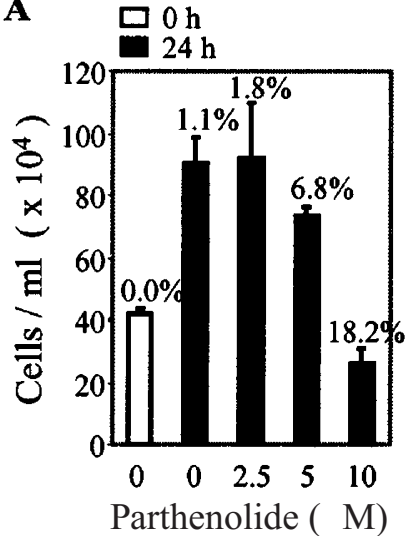

B

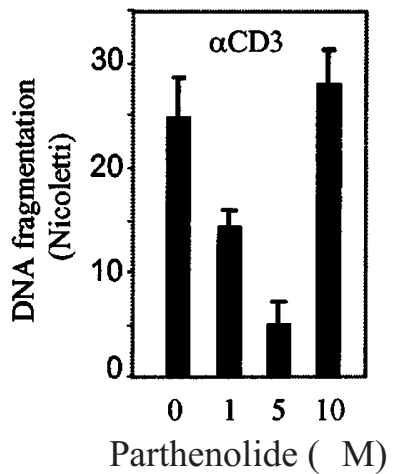

C

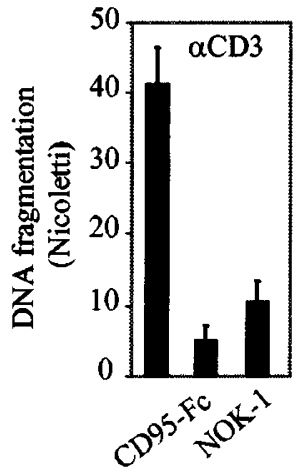

Figure 2 Toxicity analysis of parthenolide in J-27 cells. (A) J-27 cells were cultured in the absence and presence of different amounts of parthenolide as indicated for $24 \mathrm{~h}$. Numbers of live and dead cells were controlled by Trypan blue exclusion. Numbers on top of each column indicate percentage of dead (blue) cells. Results represent two replicate measurements. (B) J-27 cells were activated by $\alpha \mathrm{CD} 3$ antibodies in the absence or presence of different amounts of parthenolide for $24 \mathrm{~h}$ as described in Figure 1. Apoptotic cells were analyzed by FACS for DNA fragmentation. Error bars represent three replicate measurements. (C) J-27 cells were activated by $\alpha \mathrm{CD} 3$ antibodies in the absence or presence of CD95-Fc (50 $\mu \mathrm{g} / \mathrm{ml})$ or NOK-1 $(50 \mu \mathrm{g} / \mathrm{ml})$. Apoptotic cells were analyzed for DNA fragmentation $24 \mathrm{~h}$ after activation. Results represent two replicate measurements

to an approximate sevenfold increase in CD95L promoter activity. Administration of parthenolide significantly (70$100 \%$ ) reduced $\mathrm{PMA}$ /ionomycin- or $\alpha \mathrm{CD} 3$-induced CD95L promoter activity (Figure 4A). The activity of the CD95 promoter was only slightly increased upon T-cell activation (Figure 4B). Nevertheless, the increased promoter activity was also inhibited by parthenolide by approximate $40-60 \%$ (Figure 4B). In contrast, the Bax promoter whose activity is not positively regulated by $\mathrm{NF}-\kappa \mathrm{B},{ }^{28}$ was not down-regulated by parthenolide (Figure 4C). Thus, parthenolide reduces CD95L and CD95 expression at the transcriptional level and, consequently, attenuates AICD in J-27 cells.

\section{Parthenolide inhibits NF- $\kappa$ B binding to the CD95L promoter NF- $\kappa$ B binding sites}

Since a pronounced reduction of the CD95L promoter was seen in the presence of parthenolide in transfection studies, we further focused on the molecular mechanisms by which parthenolide down-regulates CD95L transcription. The human CD95L promoter contains two NF- $\kappa$ B binding sites at the 530 and $50^{24}$ and three Egr/NF-AT composite sites at the $-120,-180$ and -680 regions. $^{29}$ Since these sites have been shown to be important for activation-dependent promoter activity, ${ }^{24,29-33}$ an electrophoretic mobility shift assay (EMSA) was performed to analyze the effect of parthenolide on DNA-binding of transcription factors to these regulatory elements. Oligonucleotides containing the NF- $\kappa \mathrm{B}$ site at the -530 and -50 and the Egr and NF-AT site at the -120 and -180 regions were used as probes and incubated with nuclear extracts isolated from $\mathrm{J}-27$ cells activated in the presence or absence of parthenolide. Parthenolide has been shown to be a potent inhibitor of NF- $\kappa \mathrm{B}$. Thus, it blocked binding of inducible nuclear factors to the two NF- $\kappa$ B elements (Figure 5A,B). In contrast, the inducible complexes formed on the Egr- and NF-AT-binding sites (at -120 and -180 regions) were not influenced by parthenolide (Figure 5A,B).
As controls, the constitutive DNA-binding factor NF-Y was used for equal loading of proteins (Figure 5A,B). Antibody analysis demonstrated that the complexes inhibited by parthenolide contain the NF- $\kappa \mathrm{B}$ family of proteins, p50 and p65: the complex formed on -50 and -530 were partially inhibited by $\alpha$ p50 and $\alpha$ p65 antibodies (Figure 6C). The specificity of the ap65 antibody has been controlled by its capability to supershift ectopically expressed p65 protein binding on a typical NF- $\kappa$ B binding site and did not supershift other transcription factors such as SP1 (data not shown).

Recently, it was shown that SLs may directly inhibit NF$\kappa \mathrm{B}$ DNA binding by alkylating p65 at Cys38. ${ }^{22}$ Therefore, we further investigated such direct effect of parthenolide on NF- $\kappa$ B DNA binding activity in EMSA. Nuclear extracts from PMA stimulated Jurkat cells (which contain the activated nuclear form of NF- $\kappa \mathrm{B}$ ) were pre-incubated with various concentrations of parthenolide or with the solvent as control and then analyzed for DNA binding activity of NF- $\kappa \mathrm{B}$ in an EMSA. Increasing concentrations of parthenolide did not shown a significant effect on DNA binding of activated NF$\kappa \mathrm{B}$ in vitro (Figure $5 \mathrm{D}$ ). This result is in agreement with the previous study. ${ }^{20} \mathrm{~A}$ slight reduction of $\mathrm{NF}-\kappa \mathrm{B}$ binding activity was seen when $50 \mu \mathrm{M}$ parthenolide was used (Figure 5D). However, in the presence of $50 \mu \mathrm{M}$ of parthenolide, more than $80 \%$ cells die in several hours via necrosis (data not shown). Thus, inhibition of NF- $\kappa \mathrm{B}$ binding to its target site by parthenolide observed in our study is most likely regulated by blockage of NF- $\kappa$ B nuclear translocation.

To confirm that NF- $\kappa \mathrm{B}$ is involved in regulation of transcriptional activity of the two elements, we cotransfected the luciferase reporter constructs containing multiple copies of either one of the CD95L NF- $\kappa \mathrm{B}$ sites with expression vectors encoding the NF- $\kappa \mathrm{B}$ inhibitory proteins $\mathrm{I}_{\kappa} \mathrm{B} \alpha$ and $\mathrm{I}_{\kappa} \mathrm{B} \beta^{34}$ into $\mathrm{J}-27$ cells. Ectopic expression of $\mathrm{I}_{\kappa} \mathrm{B} \alpha$ or $\mathrm{I}_{\kappa} \mathrm{B} \beta$ down-regulated activities of both elements (Figure $6 \mathrm{~A})$. As a control, the Bax promoter was not suppressed by 
$\mathbf{A}$

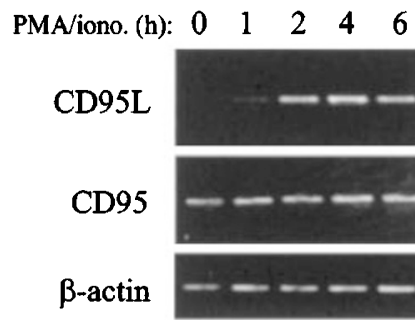

Control

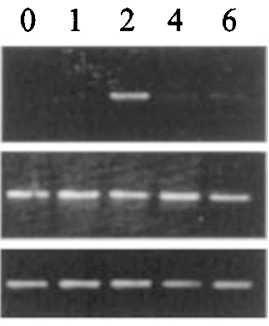

Parthenolide
B

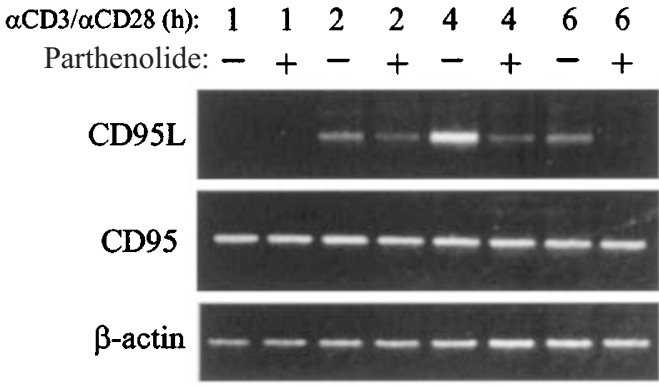

$\mathbf{C}$

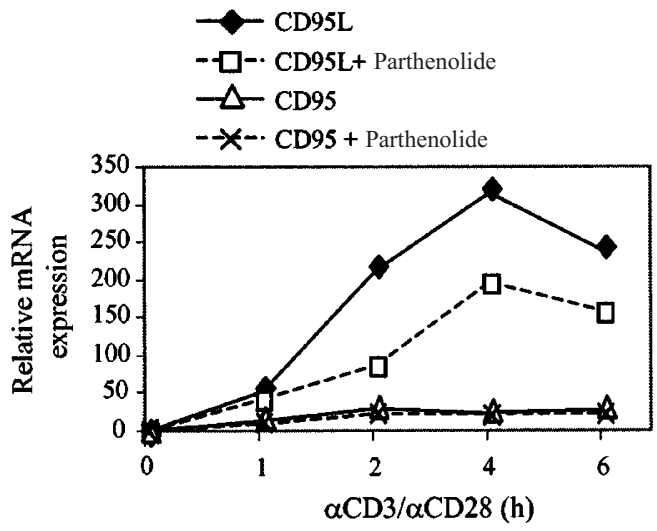

Figure 3 Parthenolide suppresses CD95L mRNA expression in activated J27 cells. (A) J-27 cells were preincubated with parthenolide $(5 \mu \mathrm{M})$ or the parthenolide solvent (control) for $1 \mathrm{~h}$ and stimulated with PMA/ionomycin for different times as indicated. Subsequently, total RNA was prepared and analyzed for CD95L and CD95 mRNA expression levels by RT-PCR. $\beta$-actin mRNA expression levels were analyzed as controls. (B) J-27 cells were pretreated with $5 \mu \mathrm{M}$ of parthenolide $(+)$ or the parthenolide solvent $(-)$ for $1 \mathrm{~h}$ and then activated by $\alpha$ CD28 and immobilized $\alpha$ CD3 antibodies for different times as indicated. The mRNA expression levels for CD95L and CD95 were analyzed by RT-PCR as in A. (C) The mRNA from $B$ was further analyzed for CD95L and CD95 mRNA expression levels by real-time quantitative PCR. The expression value of each gene under unstimulated condition (0) was set as transcription value 1 in the logarithmic scale of the relative expression of each gene. Results were internally confirmed by the comparative Ct against $\beta$-actin as the standard gene

$\mathrm{I}_{\kappa} \mathrm{B} \alpha$ and $\mathrm{I}_{\kappa} \mathrm{B} \beta$ in $\mathrm{J}-27$ cells (Figure $6 \mathrm{~A}$ ). A dose-dependent suppression of the CD95L NF- $\kappa$ B-mediated transcriptional activity was also observed (Figure 6B). It was shown that parthenolide did not affect activation of the MAP kinases JNK and $p 38^{21}$ and did not influence DNA-binding of the
$\mathbf{A}$
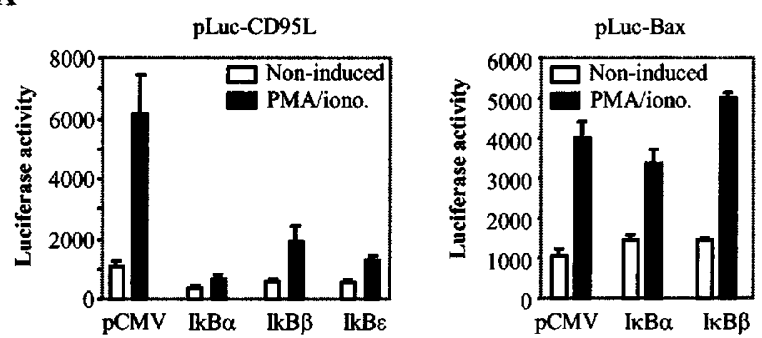

$\mathbf{B}$ pLuc-3 x-530(NF-kB)

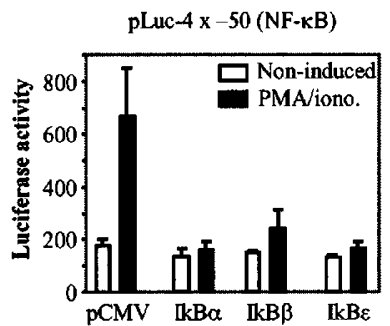

Figure 4 Parthenolide inhibits the CD95L and CD95 promoter activity in activated J-27 cells. (A). The CD95L promoter luciferase construct was transfected into J-27 cells and, after overnight culture, the cells were split and preincubated with the indicated amounts of parthenolide or the parthenolide solvent for $1 \mathrm{~h}$ and then stimulated with either $\alpha \mathrm{CD} 3$ antibodies or PMA/ ionomycin, or left unstimulated for $8 \mathrm{~h}$. The mean values and S.D. are representative for three independent transfections. (B) The CD95 promoter luciferase construct was transfected into $\mathrm{J}-27$ cells as in $\mathbf{A}$. The mean values and S.D. are representative for three independent transfections. (C) The Bax promoter luciferase reporter construct was transfected into J-27 cells as in A. Luciferase activity was determined after $8 \mathrm{~h}$ stimulation. Results are for two independent transfections

inducible transcription factor $\mathrm{AP}-1 .{ }^{35}$ Along this line, the transcriptional activity driven by three copies of a typical AP-1 element was not affected by parthenolide (Figure 6A). Thus, parthenolide can block NF- $\kappa \mathrm{B}$ binding to the CD95L $\mathrm{NF}-\kappa \mathrm{B}$ sites and attenuate transcriptional activity.

\section{Parthenolide protects apoptosis in restimulated human peripheral blood T-cells}

To further analyze the protection effect of parthenolide on $\mathrm{T}$ cell death, freshly isolated human peripheral blood T-cells were prestimulated for 6 days (referred to as day 6 T-cells) ${ }^{14}$ and subsequently restimulated via the TCR by plate-bound $\alpha \mathrm{CD} 3$ antibodies. Analysis of CD95 and CD95L mRNA expression levels of restimulated day 6 T-cells showed that both CD95 and CD95L mRNA expression were dosedependently down-regulated by parthenolide (Figure 7A). Evaluation of the CD95 and CD95L mRNA expression levels by real-time quantitative PCR showed a $50-75 \%$ reduction of CD95L mRNA expression at the $4 \mathrm{~h}$ activation time point in the presence of $1.25-5.0 \mu \mathrm{M}$ parthenolide (Figure 7B). Significant down-regulation of CD95 mRNA expression $(23-50 \%)$ by parthenolide was also observed (Figure $7 \mathrm{~B}$ ).

To further investigate the effect of parthenolide on CD95L and CD95 expression, we analyzed protein expression levels of CD95L and CD95 produced by activated T-cells. Since surface expression of human CD95L is regulated by metalloproteinases, day 6 T-cells 
A

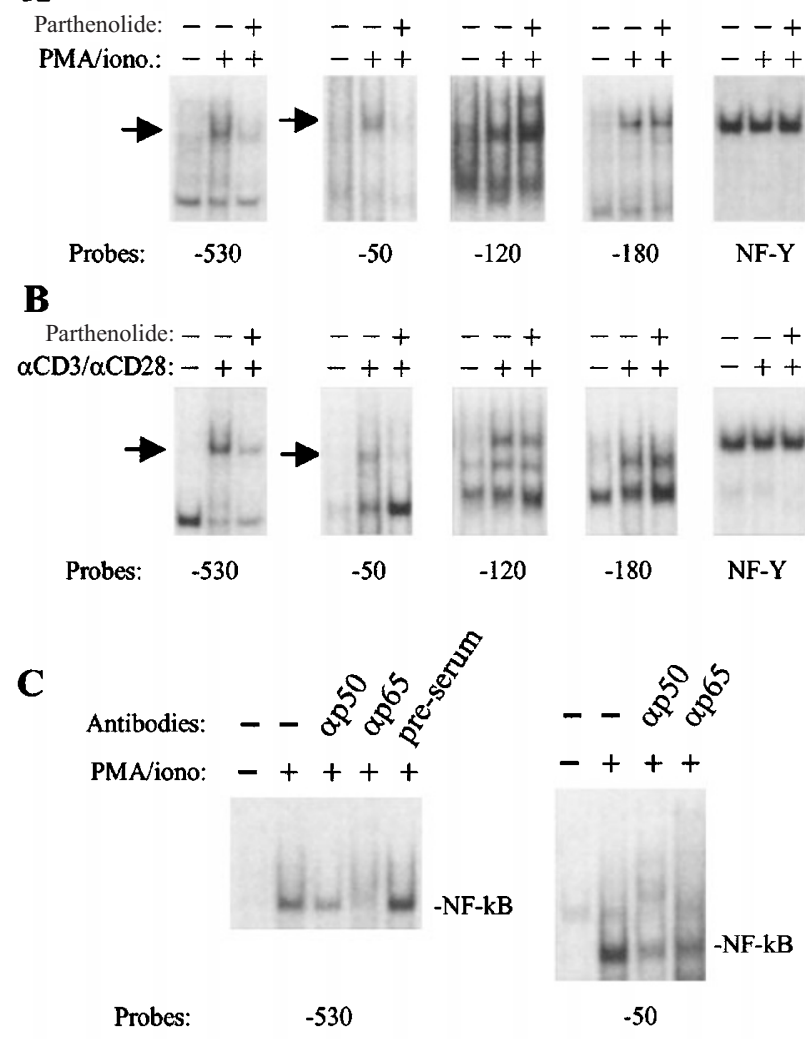

D

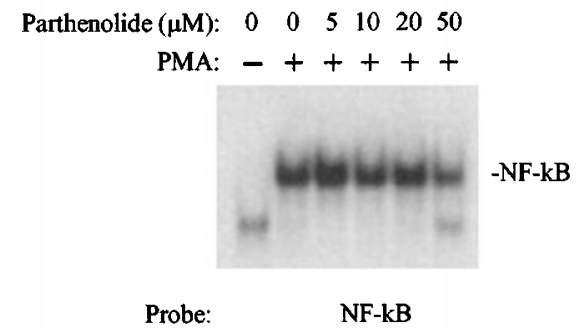

Figure 5 Parthenolide inhibits NF- $k$ B binding to the CD95L NF- $k$ B elements. (A and B) Parthenolide prevents activation-induced binding of NF- $k \mathrm{~B}$ to the CD95L NF- $\kappa$ B sites. ${ }^{32}$ P-labeled oligonucleotides containing the CD95L NF${ }_{k} \mathrm{~B}(-530,-50)$, Egr/NF-AT $(-120,-180)$ binding sequences were analyzed by EMSA. Nuclear extracts were prepared from $\mathrm{J}-27$ cells either non-induced $(-)$ or induced $(+)$ by PMA and ionomycin $(\mathbf{A})$ or by $\alpha$ CD3 and $\alpha \mathrm{CD} 28(\mathrm{~B})$ in the absence $(-)$ or presence $(+)$ of $5 \mu \mathrm{M}$ parthenolide (added $1 \mathrm{~h}$ before induction). The inducible complexes corresponding to NF- $\kappa \mathrm{B}$ were indicated by arrows. A NF-Y binding oligonucleotide was used as control for equal loading of nuclear extracts. (C) Antibody analysis of the inducible complexes formed on the CD95L NF- $\kappa$ B sites. The NF- $\kappa$ B containing complexes were analyzed by EMSA carried out in the absence $(-)$ or presence of antibodies against NF- $\kappa$ B p50 and p 65 proteins. (D) Parthenolide does not directly inhibit DNA binding of activated NF- $k$ B. Nuclear extracts from PMA activated J-27 cells were pre-incubated for $4 \mathrm{~h}$ with various concentrations of parthenolide as indicated. Subsequently these extracts were tested for DNA binding activity of NF- $\kappa$ B by EMSA using a probe containing a typical NF- $k$ B binding sequence. The NF- $k$ B containing bands are indicated

were activated via $\alpha \mathrm{CD} 3$ stimulation in the presence of metalloprotease inhibitors to increase expression of the membrane-bound ligand. As shown in Figure $8 \mathrm{~A}$, in correspondence to the reduction of CD95L mRNA levels, parthenolide inhibited $\alpha$ CD3-induced increase in CD95L protein expression levels. Restimulation of day 6 T-cells in the presence of parthenolide also resulted in approximately $50 \%$ reduction of CD95 expression (Figure 8B). Primary resting human peripheral blood $\mathrm{T}$-cells are resistant to activation induced apoptosis. ${ }^{14}$ Restimulation of day $6 \mathrm{~T}$ cells, however, results in AICD. Similar to the results obtained with J-27 cells, parthenolide suppressed AICD in restimulated peripheral blood T-cells in a dose-dependent fashion (Figure $8 \mathrm{C}$ ). A $30-55 \%$ reduction in apoptotic cells can be shown in the presence of $12.5-5.0 \mu \mathrm{M}$ parthenolide in the culture medium (Figure $8 \mathrm{C}$ ). Thus, the antiinflammatory SL parthenolide has an inhibitory effect on CD95-mediated AICD in activated T-cells.

\section{Discussion}

Parthenolide-containing herbs have been traditionally used for treatment of inflammations. The anti-inflammatory activities of these herbs are partially due to their anti-NF- $\kappa \mathrm{B}$ effects. NF- $\kappa \mathrm{B}$ is involved in transcriptional activation of CD95L gene expression in activated T-cells. In this study, we show that parthenolide suppresses the CD95L promoter activity by down-regulation of transcriptional activity of NF- $\kappa \mathrm{B}$ and, consequently, down-regulates CD95L mRNA and protein expression and CD95-mediated AICD. High dose of parthenolide is toxic as shown in our study that $10 \mu \mathrm{M}$ of parthenolide completely inhibited T-cell proliferation and resulted in an increase in dead cells. Twenty $\mu \mathrm{M}$ parthenolide kill $80-90 \%$ cells in $24 \mathrm{~h}$ (data not shown). At a higher dose $(<10 \mu \mathrm{M})$ of parthenolide, cells die via necrosis because no increase of DNA fragmentation could be detected when cells were treated with parthenolide alone (data not shown).

CD95 mRNA is constitutively expressed in Jurkat T-cells and is highly expressed in pre-activated peripheral blood Tcells. Nevertheless, real-time quantitative RT-PCR revealed that CD95 mRNA expression is further upregulated upon activation of Jurkat T-cells or after restimulation of preactivated day $6 \mathrm{~T}$-cells. NF- $\kappa \mathrm{B}$ regulatory elements have been found in the CD95 promoter. ${ }^{27,36}$ When binding of NF$\kappa \mathrm{B}$ was inhibited by the blockade of $\kappa \mathrm{B}$ translocation or mutagenesis of the $\kappa \mathrm{B}$ site, activation-dependent CD95 upregulation in Jurkat T-cells was lost. ${ }^{27}$ In the presence of parthenolide, approximately $15-20 \%$ down-regulation of CD95 mRNA levels were seen in Jurkat. The effect of parthenolide on CD95 expression of human peripheral blood T-cells is more significant: approximately $50 \%$ reduction of both CD95 mRNA and CD95 cell surface expression in restimulated day 6 T-cells was observed. Thus, parthenolide-mediated down-regulation of AICD may also involve CD95, although to a lesser extent than CD95L.

$\mathrm{NF}-\kappa \mathrm{B}$ transcription factors are key regulators of immune, inflammatory and acute phase responses and have been implicated in the control of cell proliferation and apoptotic signaling. A vast array of stimuli including TCR stimulation, certain environmental stressors, chemicals, ionizing and UV irradiation, chemotherapeutic agents, proto-oncogenes, and oxidative stress can induce NF- $\kappa \mathrm{B}$ activities. ${ }^{37,38}$ However, the role of $\mathrm{NF}-\kappa \mathrm{B}$ in apoptosis 
A

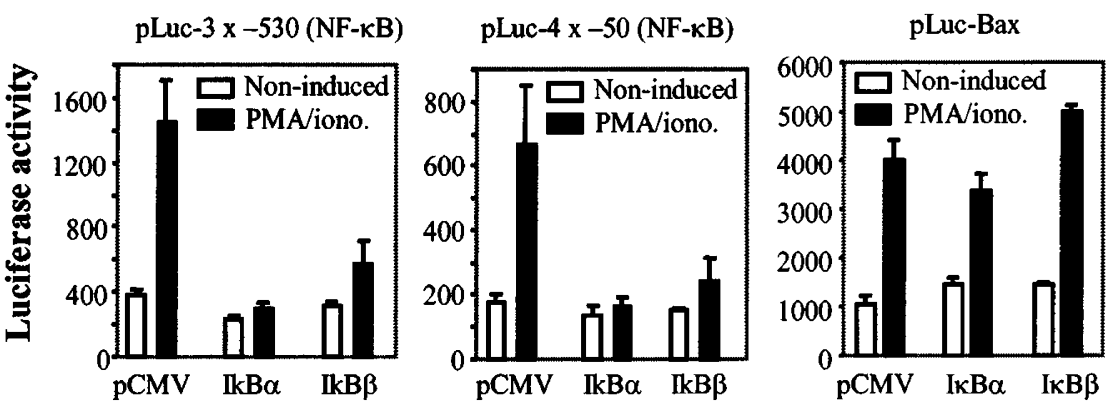

B
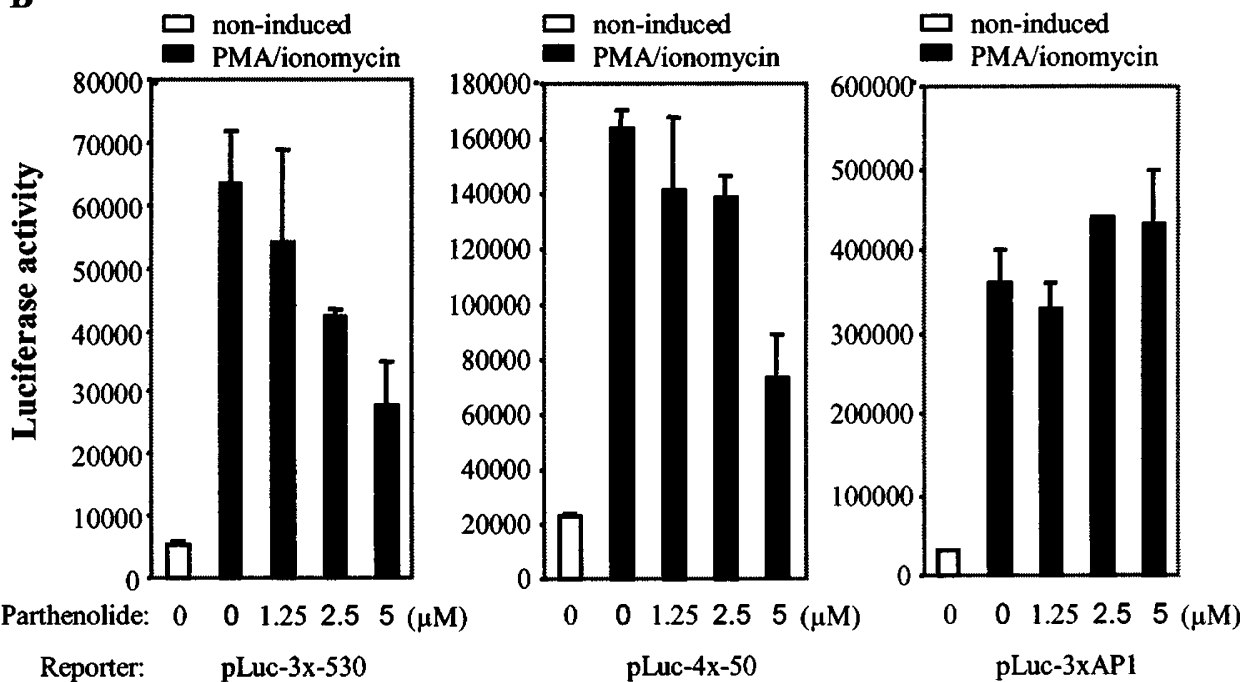

Figure 6 Parthenolide inhibits transactivation mediated by the CD95L NF- $\kappa$ B elements. (A) J-27 cells were transiently transfected with the luciferase reporter constructs containing three copies of the -530 element or four copies of the -50 element together with the NF- $\kappa \mathrm{B}$ inhibitory protein I $\kappa \mathrm{B} \alpha$ and I $\kappa \mathrm{B} \beta$ expression vectors. The empty vector $\mathrm{pCMV}$ was added to have equal amounts of DNA in the transfections. Transfection efficiency was controlled by cotransfection with the GFP plasmid. After overnight culture, the transfected cells were split and stimulated with PMA/ionomycin or left unstimulated for $8 \mathrm{~h}$. A luciferase reporter plasmid containing the Bax promoter was transfected in the same experiment as a control. The mean values and S.D. are representative for three independent transfections. (B) The multiple copies of -530 or -50 luciferase reporter constructs were transfected into J-27 cells and after overnight culture, the cells were split and pre-incubated with different amounts of parthenolide or the parthenolide solvent $(0)$ for $1 \mathrm{~h}$ and then, stimulated with PMA/ionomycin or left unstimulated for $8 \mathrm{~h}$. The mean values and S.D. are representative for three independent transfections. A luciferase reporter construct containing three copies of the AP-1 consensusbinding site was used as specificity control of the effect of parthenolide. Results represent the average of three to five independent transfection experiments

remains controversial. Both activities have been found: acceleration of apoptosis and protection from apoptosis (for review see ${ }^{39}$ ). Whether $\mathrm{NF}-\kappa \mathrm{B}$ promotes or inhibits apoptosis appears to depend on the specific cell type and the type of inducer. SLs are potent inhibitors of NF- $\kappa \mathrm{B} .{ }^{20-22}$ Thus, our study provides clear evidence showing that the pro-inflammatory transcription factor $\mathrm{NF}-\kappa \mathrm{B}$ exerts a proapoptotic role in AICD in T-cells.

Investigation of the molecular basis by which parthenolide inhibits NF- $\kappa \mathrm{B}$ activity has revealed two mechanisms: direct inhibition of DNA binding by alkylating p65 at cysteine $38^{22}$ and a second mechanism targeting the $I_{\kappa} \mathrm{B}$ kinase. ${ }^{20,21}$ Parthenolide possesses two reactive centers in form of an exomethylene group and an epoxide ring required to irreversibly inactivate its target molecules. ${ }^{20}$ Garcia-Pineres et al. ${ }^{22}$ demonstrated that the major effect of parthenolide on NF- $\kappa$ B DNA binding activity occurs via alkylation of p65 at cystein 38 and only a partial inhibition of
$I_{\kappa} \mathrm{B}$ degradation was seen in Jurkat T-cells. An opposite observation was reported by Hehner et al. ${ }^{20}$ showing that inhibition of NF- $\kappa \mathrm{B}$ binding to its target site by parthenolide is due to prevention of $I \kappa \mathrm{B}$ degradation and parthenolide itself does not interfere with DNA binding activity of activated $\mathrm{NF}-\kappa \mathrm{B} .{ }^{20}$ We have also investigated whether parthenolide exerts a direct inhibitory effect on DNA binding activity by adding different doses of parthenolide to the nuclear extracts. In agreement with the report of Hehner et al., ${ }^{20}$ we did not observe a significant inhibitory effect of parthenolide on DNA binding activity of activated NF- $\kappa$ B. Garcia-Pineres et al. ${ }^{22}$ performed their experiments with $20 \mu \mathrm{M}$ of parthenolide which can be quite toxic to the $\mathrm{T}$ cells. However, we do not exclude the possibility that parthenolide does, in part, exert a direct inhibitory effect on NF- $\kappa$ B DNA binding activity via alkylation.

SL parthenolide was shown to prevent the MAP3 kinase NIK and MEKK1 (identified as an interactor and activator of 


\section{A}

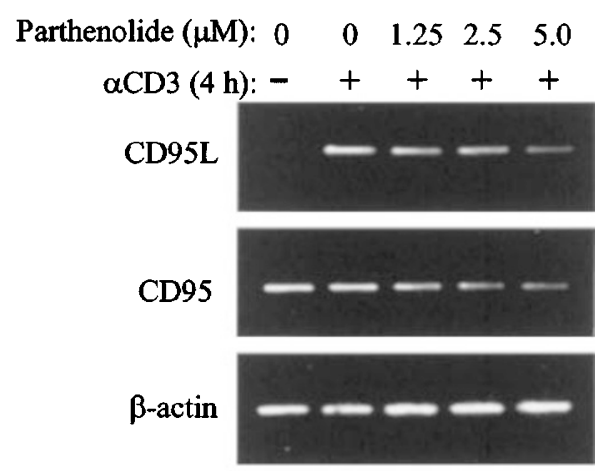

B

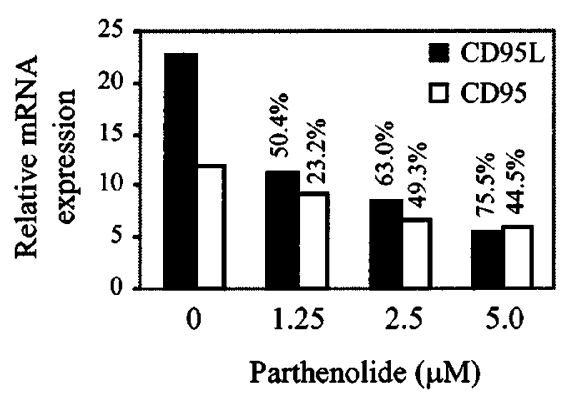

Figure 7 Parthenolide inhibits CD95L and CD95R mRNA expression in activated peripheral human T cells. (A) Human peripheral blood T cells were pre-incubated with different doses of parthenolide or the parthenolide solvent (0) for $1 \mathrm{~h}$ and stimulated with $\alpha \mathrm{CD} 3$ for $4 \mathrm{~h}$. The mRNA expression levels for CD95L and CD95 were analyzed by RT-PCR. (B) Above RNAs were further analyzed by real-time quantitative RT-PCR. The expression value of each gene under unstimulated condition was set as transcription value 1 in the logarithmic scale of the relative expression of each gene. Results were internally confirmed by the comparative $\mathrm{Ct}$ against $\beta$-actin as the standard gene. Numbers on top of each column represent percentage of inhibition of mRNA expression in the presence of parthenolide

both IKK $\alpha$ and IKK $\beta$ ) induced activation of both IKKs, but does not affect activation of p38 and c-Jun N-terminal kinase. ${ }^{21}$ Parthenolide also does not interfere with activity of the Src family protein tyrosine kinases $\mathrm{p} 59^{\text {fyn }}$ and p60 $0^{\text {src }} .20$ The specificity of parthenolide has been also documented by other investigators showing that it does not influence the activity of other transcription factors such as AP-1, RBP-J $\kappa$, and Oct-1. ${ }^{21,35}$ Since parthenolide displays a relatively high degree of specificity for $\mathrm{NF}-\kappa \mathrm{B}$, it may be justified in the future to develop parthenolides as new antiapoptotic drugs against AICD in T-cells.

\section{Materials and Methods}

\section{Cell line and cell culture}

The Jurkat T-leukemia cell clone J-27 was cultured in RPMI 1640 medium (GIBCO laboratories, Grand Island, NY, USA) supplemented with $10 \% \mathrm{FCS}, 50 \mu \mathrm{g} / \mathrm{ml}$ gentamicin (GIBCO), $6 \mathrm{mM}$ HEPES (GIBCO, $1 \mathrm{M}$ solution), and $2 \mathrm{mM}$ L-glutamine (GIBCO, $200 \mathrm{mM}$ solution) at $37^{\circ} \mathrm{C}$ and $5 \% \mathrm{CO}_{2}$. Primary human T-cells were cultured in the presence of IL-2 as described previously. ${ }^{14}$

\section{Antibodies}

$\alpha$ APO-1 antibody has been made in our laboratory. ${ }^{40}$ The goat anti-mouse-PE was purchased from Jackson Immuno Research Laboratory Inc. The ap50 antibody was purchased from Santa Cruz Biotechnology, Inc. (Santa Cruz, CA, USA). The $\alpha$ NF- $\kappa \mathrm{B} / \mathrm{p} 65$ was purchased from BIOMOL Research Laboratories, Inc. (Butler Pike, PA, USA). PE-labeled IgG antibody Streptavidin-PE, NOK-1 and Biotin-labeled NOK-1 antibodies were purchased for BDPharmingen (San Diego, CA, USA). The hybridoma secreting $\alpha$ CD28 was kindly provided by G Moldenhauer (DKFZ, Heidelberg, Germany).

\section{Purification of primary human T-lymphocytes}

PBMC were collected from healthy adult donors. The mononuclear cells were isolated over Ficoll-Hypaque (Biochrom, Berlin, Germany), washed three times with PBS, and incubated at DMEM for $1 \mathrm{~h}$ in plastic tissue culture dishes at $37^{\circ} \mathrm{C}$ in a $5 \% \mathrm{CO}_{2}$ incubator. Non-adherent lymphocytes cells were collected from the plastic dishes. T-cells were purified from the mixed lymphocyte population up to $90 \%$ purity using TB-Sep nylon wool columns (Cell-Tech $\mathrm{GmbH}$, Bad-Dürkheim, Germany) according to the manufacturer's instruction.

\section{AICD}

Freshly isolated blood T-cells were stimulated by PHA and cultured in the presence of IL-2 for 6 days as described. ${ }^{14}$ The day 6 T-cells were then treated without or with different doses of parthenolide (Sigma, St. Louis, MO, USA) for $1 \mathrm{~h}$ and subsequently cultured in 96-well-flat-bottomed plates coated with $\alpha$-CD3 (OKT3, $50 \mu \mathrm{g} / \mathrm{ml}$ ). Cell death was assessed by propidium iodide (PI) uptake and analyzed by FACS. ${ }^{14}$

J-27 T leukemia cells were induced either with PMA $(10 \mathrm{ng} / \mathrm{ml})$ (Sigma, St. Louis, MO, USA) and ionomycin $(0.5 \mu \mathrm{M})$ (Calbiochem, Bad Soden, Germany) or with plate-bound $\alpha$-CD3 (OKT3, $50 \mu \mathrm{g} / \mathrm{ml}$ ) for $24 \mathrm{~h}$ in the presence of parthenolide or equal amounts of the solvent ethanol. For controls, J-27 cells were stimulated in the absence or presence of CD95-Fc $(50 \mu \mathrm{g} / \mathrm{ml})^{16}$ or NOK1 $(50 \mu \mathrm{g} / \mathrm{ml})$ for $24 \mathrm{~h}$. Apoptotic nuclei were measured by propidium iodide $(\mathrm{PI})$ uptake. $^{14}$

\section{Analysis of surface CD95L and CD95R protein expression}

For CD95L analysis, day 6 T-cells were activated by plate-coated $\alpha \mathrm{CD} 3$ (OKT3, $40 \mu \mathrm{g} / \mathrm{ml}$ ) in the presence of matrix metalloproteinase inhibitors specific for CD95L (MMP inhibitor II, $4 \mu \mathrm{g} / \mathrm{ml}$, Calbiochem, La Jolla, CA, USA). After indicated times, cells were collected by centrifugation, washed once with PBS. $5 \times 10^{5}$ cells were resuspended in $100 \mu \mathrm{l}$ PBS containing 5\% FCS. The cells were incubated with Biotin-labeled $\alpha$ CD95L antibody (NOK-1, $0.05 \mu \mathrm{g} / \mathrm{ml}$ ) at $4^{\circ} \mathrm{C}$ for $15 \mathrm{~min}$. Bound antibodies were detected by adding $100 \mu \mathrm{l}$ PBS containing $0.025 \mu \mathrm{g} / \mathrm{ml}$ Streptavidin-PE and incubated at $4^{\circ} \mathrm{C}$ for a further $15 \mathrm{~min}$. Cells were washed once with PBS and resuspended in $200 \mu \mathrm{l}$ PBS and subjected to FACS (FL2 Histogram) analysis. For CD95 analysis, day 6 T-cells were activated by $\alpha$ CD3 in the presence and absence of parthenolide as above. After $16 \mathrm{~h}$ activation, the cells $\left(2 \times 10^{5}\right)$ were collected and suspended in $50 \mu \mathrm{l}$ PBS containing $1 \mu \mathrm{g} /$ $\mathrm{ml}$ of $\alpha$ APO- 1 antibody and incubated at $4{ }^{\circ} \mathrm{C}$ for $15 \mathrm{~min}$. Fifty $\mu \mathrm{l}$ of PBS containing 1:200 diluted goat $\alpha$-mouse-PE were added to the cells and incubated at $4{ }^{\circ} \mathrm{C}$ for a further $15 \mathrm{~min}$. Cells were washed once with PBS and resuspended in $100 \mu \mathrm{l}$ PBS and subjected to FACS analysis. 
$\mathbf{A}$

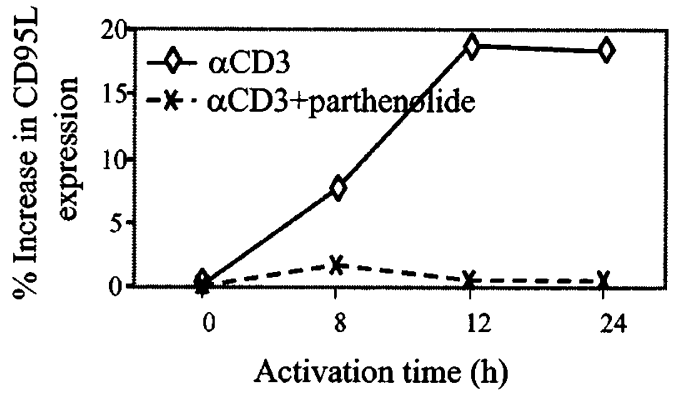

B

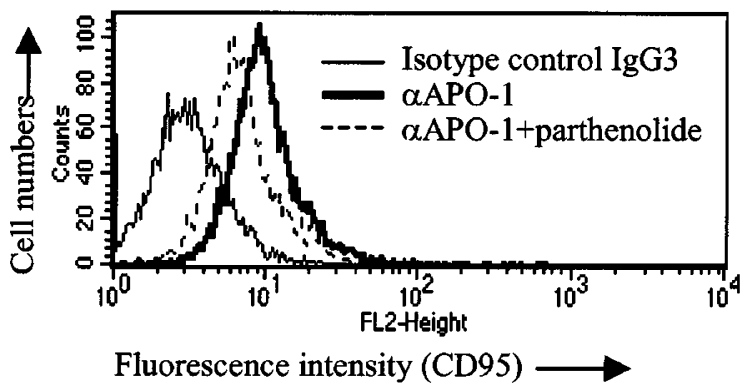

C

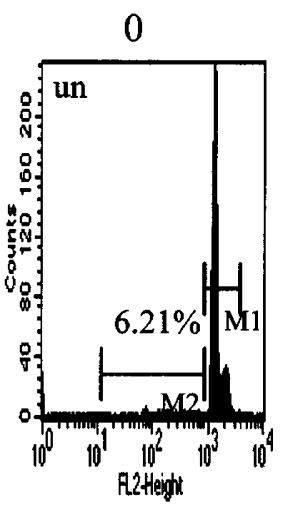

0

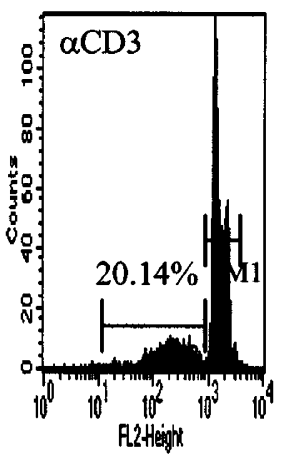

Parthenolide $(\mu \mathrm{M})$
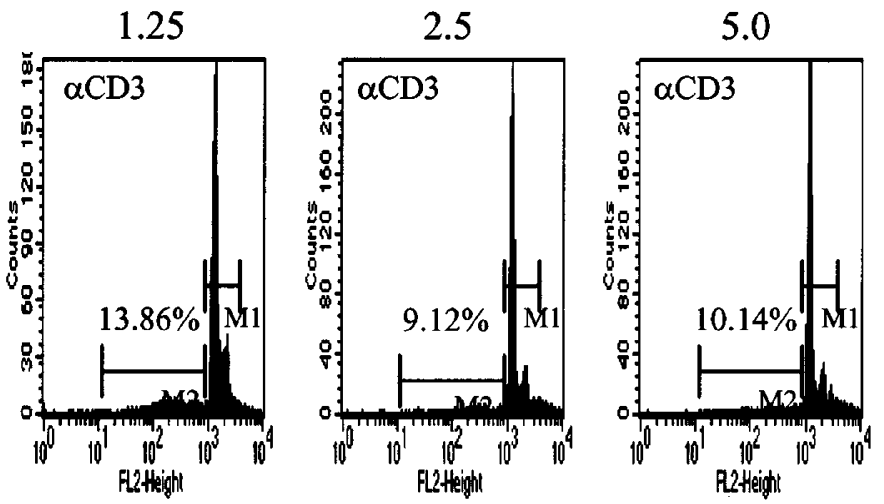

Figure 8 Parthenolide inhibited CD95L and CD95 expression and down-regulates AICD in reactivated day 6 T cells. (A) Fresh isolated human peripheral blood T cells were preactivated for 6 days as previously described. ${ }^{14}$ The day 6 T cells were restimulated by $\alpha \mathrm{CD} 3$ in the absence or presence of $2.5 \mu \mathrm{M}$ parthenolide (added $1 \mathrm{~h}$ before activation) for different times as indicated. The cells were harvested and analyzed for cell-surface expression levels of CD95L protein. The result was represented as percentage of $\alpha$ CD3-induced increase in CD95L expression (18.5 $\pm 4.3 \%$ CD95L positive in un-restimulated T cells). (B) The expression levels of CD95 were measured by FACS using the CD95-specific antibody $\alpha$ APO-1 and an isotype-matched control IgG3 antibody. A representative result from day 6 T cells restimulated for $16 \mathrm{~h}$ in the presence or absence of $1.25 \mu \mathrm{M}$ parthenolide (added $1 \mathrm{~h}$ before stimulation) is shown. (C) The day $6 \mathrm{~T}$ cells were restimulated by $\alpha \mathrm{CD} 3$ in the absence or presence of different amounts of parthenolide as indicated (added $1 \mathrm{~h}$ before activation). Apoptotic cells were measured by PI uptake after $16 \mathrm{~h}$ restimulation. Numbers represent percentage of apoptotic cells

\section{RNA preparation}

$\mathrm{J}-27$ cells and the peripheral blood T-cells were pre-cultured with different doses of parthenolide or a equal amounts of solvent ethanol for $1 \mathrm{~h}$ and then stimulated for indicated times with plate-bound $\alpha$-CD3 antibodies or with PMA (10 $\mathrm{ng} / \mathrm{ml})$ (Sigma, St Louis, MO, USA) and ionomycin $(0.5 \mu \mathrm{M})$ (CalBiochem, La Jolla, CA, USA). RNA was isolated using the RNeasy kit (Qiagen $\mathrm{GmbH}$, Hilden, Germany) according to the manufacture $s$ instructions.

\section{Normal RT - PCR}

One $\mu \mathrm{g}$ of total RNA was reverse transcribed using the RT-PCR kit (Perkin Elmer, Foster City, CA, USA). Aliquots were amplified in a DNA thermocycler (Startagene, Heidelberg, Germany) with $2.5 \mathrm{U}$ recombinant Taq polymerase (Sigma, St Louis, MO, USA). Amplification products were separated by electrophoresis on $1.2 \%$ agarose gels. Primers used are: for CD95L, sense 5'-ATAGGATCCATGTTTCTGCTCTTCCACCTACAGAAGGA-3' and antisense $5^{\prime}$ ATAGAATTCTGACCAAGAGAGGCTCAGATACGTTGAC-3'; for CD95, sense 5'-CAAGTGCAGATGTAAAC-3' and antisense 5'TGAAGTTGATGCCAATTACG- $3^{\prime}$ and for $\beta$-actin, sense $5^{\prime}$ TGACGGGGTCACCCACACTGTGCCCATCTA-3' and antisense $5^{\prime}$ CTAGAATTTGCGGTGGACGATGGAGGG-3'.

\section{Real-time quantitative PCR}

Real-time quantitative PCR has been previously described in detail. ${ }^{41}$ The primers and fluorescent-labeled probes used in these studies are CD95L primers: forward 5'-AAAGTGGCCCATTTAACAGGC-3', reverse 5'-AAAGCAGGACAATTCCATAGGTG-3', probe 5'TCCAACTCAAGGTCCATGCCTCTGG-3'; CD95 primers: forward 5'ACTGTGACCCTTGCACCAAAT-3', reverse 5'-GCCACCCCAAGTTAGATCTGG-3', probe 5'-AATCATCAAGGAATGCACACTCACCAGCA3'; $\beta$-actin primers: forward 5'-ACCCACACTGTGCCCATCTACGA-3', reverse 5'-CAGCGGAACCGCTCATTGCCAATGG-3', probe 5'ATGCCCTCCCCCATGCCATCCTGCGT-3'.

PCR was performed in a $12.5 \mu \mathrm{l}$ reaction mixture (PCR kit from Eurogentech, Belgium) that contained $0.08 \mu \mathrm{g}$ of reverse transcribed CDNA, $1.25-7.5 \mathrm{pM}$ forward primers, $22.5 \mathrm{pM}$ reverse primers and $5 \mathrm{pM}$ probe. For each sample three PCR were performed. The resulting relative increase in reporter fluorescent dye emission was monitored by the TagMan-system (GeneAmp 5700 sequence detection system and software, Perkin Elmer, Foster City, CA, USA). The level of the CD95L and CD95 mRNA, relative to $\beta$-actin mRNA, was calculated using the formula:

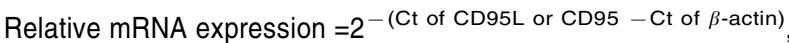
where $\mathrm{Ct}$ is the threshold cycle value. 


\section{Preparation of nuclear extracts and EMSA}

$\mathrm{J}-27$ cells were preincubated with $5 \mu \mathrm{M}$ parthenolide or equal amounts of the solvent ethanol for $1 \mathrm{~h}$ and then stimulated by PMA $(10 \mathrm{ng} / \mathrm{ml})$ and ionomycin $(0.5 \mu \mathrm{M})$ for $1.5 \mathrm{~h}$ or by $\alpha \mathrm{CD} 3$ (plate coated with OKT3, $50 \mu \mathrm{g} / \mathrm{ml})$ and $\alpha \mathrm{CD} 28(2.5 \mu \mathrm{g} / \mathrm{ml})$. Nuclear proteins were isolated as described previously. ${ }^{24}{ }^{32} \mathrm{P}$-labeled oligonucleotides containing the CD95L NF- $\kappa$ B sites at the promoter -530 and -50 region $^{24}$ and the Egr and NF-AT sites at the promoter -120 and -180 region $^{29}$ were analyzed by EMSA as described. ${ }^{24}$ NF-Y $(E \alpha)$ (CACCTTTTAACCAATCAGAAAAAT) and the NF- $\kappa$ B consensus site (TCAGAGGGGACTTTCCGAGAGGCG), were used for controls.

\section{Plasmid constructs and transient transfections}

Luciferase reporter constructs containing the $0.86-\mathrm{kb} C D 95 \mathrm{~L}$, promoter or multimers of the CD95L NF- $\kappa$ B binding sites at the -530 and -50 regions were used as published previously. ${ }^{24}$ The 1.71-kb CD95 promoter luciferase reporter was constructed by cloning the human APO-1 gene ${ }^{42} \mathrm{HindlII} / \mathrm{Sacll}$ fragment $(-1780$ to -70$)$ into the Luciferase reporter plasmid. Three copies of the AP-1 binding site from SV40 enhancer (CGGTTGCTGACTAATTG) were generated by ligation of the DNA sequence into the multiple-cloning site of pTATALuc vector. All constructs were confirmed by sequencing analysis. The pLuc-Bax promoter reporter plasmid ${ }^{43}$ was kindly provided by $\mathrm{ML}$ Schmitz (German Cancer Research Center G0200, Heidelberg, Germany). The $I_{\kappa} \mathrm{B} \alpha$ and $I_{\kappa} \mathrm{B} \beta$ expression plasmids ${ }^{34}$ were kindly provided by A Israel (Institut Pasteur, Paris, France).

J-27 cells were transfected by electroporation as previously described. ${ }^{24}$ After overnight recovering, the cells were divided and treated with parthenolide or the solvent ethanol for $1 \mathrm{~h}$ and than further cultured in the absence or presence of PMA $(10 \mathrm{ng} / \mathrm{ml})$ and ionomycin $(0.5 \mu \mathrm{M})$ or in $\alpha \mathrm{CD} 3(\mathrm{OKT} 3,50 \mu \mathrm{g} / \mathrm{ml})$ coated plates for $8 \mathrm{~h}$. Transfection efficiency was controlled by cotransfection with $0.5 \mu \mathrm{g}$ of a green fluorescence protein (GFP) expression plasmid (Clontech, Palo Alto, CA, USA). Luciferase activity was determined in $10 \mu \mathrm{l}$ of cell extract using the luciferase assay substrate (Promega Corp., Heidelberg, Germany) with a Duolumat LB9507 luminometer (Berthold, Germany).

\section{Acknowledgements}

We thank S Parg and WW Müller for technical help, Drs A Israel and ML Schmitz for providing $\mathrm{I}_{\kappa} \mathrm{B} \alpha$ and $\mathrm{I}_{\kappa} \mathrm{B} \beta$ expression plasmids and the plucBax plasmid.

\section{References}

1. Nagata S (1997) Apoptosis by death factor. Cell 88: 355-365.

2. Krammer HP. (2000). CD95́s deadly mission in the immune system. Nature 407: $789-795$.

3. Krammer HP (1999). Adv. Immunol. 71: 163-210.

3. Watanabe-Funkunaga R, Brannan Cl, Copeland NG, Jenkins NA and Nagata S (1992) Lymphoproliferation disorder in mice explained by defects in Fas antigen that mediates apoptosis. Science 245: $301-317$.

5. Lynch DH, Watson ML, Alderson MR, Baum PR, Miller RE, Tough T, Gibson M, Davis-Smith T, Smith CA, Hunter K, Bhat D, Din W, Goodwin RG and Seldin MF (1994). The mouse Fas-ligand gene is mutated in gld mice and is part of a TNF family gene cluster. Immunity 1: 131-136.

6. Fisher GH, Rosenberg FJ, Straus SE, Dale JK, Middelton LA, Lin AY, Strober W, Lenardo MJ and Puck JM (1995) Dominant interfering Fas gene mutations impair apoptosis in a human autoimmune lymphoproliferative syndrome. Cell 81:935946.
7. Rieux-Lancat F, Le Deist F, Hivroz C, Roberts IAG, Denatin KM, Fischer A and Villarty JP (1995) Mutations in Fas associated with human lymphoproliferative syndrome and autoimmunity. Science 268: 1347-1349.

8. De Maria R and Testi R. (1998) Fas-FasL interactions: a common pathogenetic mechanism in organ-specific autoimmunity. Immunol. Today 19: 121-125.

9. Sabelko-Downes KA, Gimenez MT, Suvannavejh GC, Miller SD and Russell JH. (2000) Genetic control of pathogenic mechanisms in autoimmune demyelinating disease. J. Neuroimmunol. 110: 168-176.

10. Badley AD, Pilon AA, Landay A and Lynch DH (2000) Mechanisms of HIVassociated lymphocyte apoptosis. Blood 96: 2951-2964.

11. Suda T, Takahashi T, Golstein P and Nagata S (1993) Molecular cloning and expression of the Fas ligand, a novel member of the TNF family. Cell 75: 11691178.

12.Faris M, Latinis KM, Kempiak S, Koretzky GA and Nel A (1998) Stress-induced Fas ligand expression in T-cells is mediated through MEK kinase 1-regulated response element in the Fas ligand promoter. Mol. Cell. Biol. 18: 5414-5424.

13. Kasibhatla S, Brunner T, Genestier L, Echeverri F, Mahboubi A and Green DR (1998) DNA damaging agents induce expression of Fas ligand and subsequent apoptosis in T lymphocytoes via the activation of NF- $k$ B and AP-1. Mol. Cell. 1: $543-551$.

14. Klas C, Debatin KM, Jonker RR and Krammer PH (1993) Activation interferes with the APO-1 pathway in mature human T-cells. Int. Immunol. 5: 625-630.

15. Li-Weber M and Krammer PH (2002) The death of a T-cell: expression of the CD95 ligand. Cell Death Differ. 9:101-103.

16. Dhein, J, WalczakH, Baümler C, Debatin KM and Krammer PH (1995) Autocrine T-cell suicide mediated by APO-1(Fas/CD95). Nature 373: 438-441.

17. Heinrich M, Robles M, West JE, Ortiz de Montellano BR and Rodriguez E. (1998) Ethnopharmacology of Mexican asteraceae (Compositae). Annu. Rev. Pharmacol. Toxicol. 38: 539-565.

18. Heinrich M (2000) Ethnobotany and its role in drug development. Phytother. Res. 14: $479-488$

19. Pittler MH, Vogler BK and Ernst E. (2000) Feverfew for preventing migraine. Cochrane Database Syst. Rev. 3: CD002286.

20. Hehner SP, Heinrich M, Bork PM, VogtM, Ratter F, Lehmann V, Schulze-Osthoff K, Droge W and Schmitz ML (1998) Sesquiterpene lactones specifically inhibit activation of NF-kappa B by preventing the degradation of I kappa B-alpha and I kappa B-beta. J. Biol. Chem. 273: 1288-1297.

21. Hehner SP, Hofmann TG, Droge W and Schmitz ML (1999) The antiinflammatory sesquiterpene lactone parthenolide inhibits NF-kappa B by targeting the I kappa B kinase complex. J. Immunol. 163: 5617-5623.

22. Garcia-Pineres AJ, Castro V, Mora G, Schmidt TJ, Strunck E, Pahl HL and Merfort I (2001) Cysteine 38 in p65/NF-kappaB plays a crucial role in DNA binding inhibition by sesquiterpene lactones.J. Biol. Chem. 276: 39713-39720.

23. Pahl HL (1999) Activators and target genes of Rel/NF- $k B$ transcription factors. Oncogene 18: 6853-6866.

24. Li-Weber M, Laur O, Dern K and Krammer PH. (2000) T-cell activation-induced and HIV tat-enhanced CD95(APO-1/Fas) ligand transcription involves NF- $\kappa$ B. Eur. J. Immunol. 30: 661-670.

25. Li CJ, Friedman DJ, Wang C, Metelev V and Pardee AB (1995) Induction of apoptosis in uninfected lymphocytes by HIV-1 Tat protein. Science 268: 429431.

26. Westendorp MO, Frank R, Ochsenbauer C, Stricker K, Dhein J, Walczak H, Debatin KM and Krammer PH (1995) Sensitization of T-cells to CD95-mediated apoptosis by HIV-1 Tat and gp120. Nature 375: 497500.

27. Chan H, Bartos DP and Owen-Schaub LB (1999) Activation-dependent transcriptional regulation of the human Fas promoter requires NF-kappaB p50-p65 recruitment. Mol. Cell. Biol. 19: 2098-2108.

28. Bentires-Alj M, Dejardin E, Viatour P, Van Lint C, Froesch B, Reed JC, Merville MP and Bours V (2001) Inhibition of the NF-kappa B transcription factor increases Bax expression in cancer cell lines. Oncogene 20: 2805-2813.

29. Li-Weber M, Laur O, and Krammer PH. (1999) Novel Egr/NF-AT composite sites mediate activation of the CD95 (APO-1/Fas) ligand promoter in response to Tcell stimulation. Eur. J. Immunol. 29: 3017-3027.

30. Latinis KM, Norian LA, Eliason SL and Koretzky GA (1997) Two NFAT transcription factor binding sites participate in the regulation of CD95(Fas) ligand expression in activated human T-cells. J. Biol. Chem. 272: 31427-31434.

31. Holtz-Heppelmann CJ, Algeciras A, Badley AD and Paya CV. (1998) Transcriptional regulation of the human FasL promoter-enhancer region. J. Biol. Chem. 273: 4416-4423. 
32. Mittelstadt PR and Ashwell JD (1998) Cyclosporin A-sensitive transcription factor Egr-3 regulates Fas ligand expression. Mol. Cell. Biol. 18: 744-751.

33. Mittelstadt PR and Ashwell JD (1999) Role of Egr-2 in up-regulation of Fas ligand in normal T-cells and aberrant double-negative Ipr and gld T-cells. J. Biol. Chem. 274: $3222-3227$.

34.Weil R, Laurent-Winter $\mathrm{C}$ and Israel A (1997) Regulation of $\mathrm{I}_{\kappa} \mathrm{B} \beta$ degradation. J. Biol. Chem. 272: $9942-9949$

35. Bork PM, Schmitz ML, Kuhnt M, Escher C and Heinrich M (1997) Sesquiterpene lactone containing Mexican Indian medicinal plants and pure sesquiterpene lactones as potent inhibitors of transcription factor NF- $\kappa$ B. FEBS Lett. 402: 8590.

36. Zheng Y, Ouaaz F, Bruzzo P, Singh V, Gerondakis S and Beg AA (2001) NFkappa B RelA (p65) is essential for TNF-alpha-induced fas expression but dispensable for both TCR-induced expression and activation-induced cell death. J. Immunol. 166: 4949-4957.

37. Gius D, Botero A, Shah S and Curry HA (1999) Intracellular oxidation/reduction status in the regulation of transcription factors NF- $\kappa$ B and AP-1. Toxicol. Lett. 106: $93-106$.
38. Mercurio $\mathrm{F}$ and Manning AM (1999) NF- $\kappa$ B as a primary regulator of the stress response. Oncogene 18: 6163-6171.

39. Barkett Mand Gilmore TD (1999) Control of apoptosis by Rel/NF- $\kappa$ B transcription factors. Oncogene 18: 6910-6924.

40. Trauth BC, Klas C, Peters AM, Matzku S, Moller P, Falk W, Debatin KM and Krammer PH. (1989) Monoclonal antibody-mediated tumor regression by induction of apoptosis. Science 245: 301-305.

41. Heid CA, Stevens J, Livak KJ and Williams PM (1996) Real time quantitative PCR. Genome Res. 6: 986-994.

42. Behrmann I, Walczak H and Krammer PH (1994) Structure of the human APO-1 gene. Eur. J. Immunol. 24: 3057-3062.

43. Hofmann TG, Moller A, Sirma H, ZentgrafH, Taya Y, Droge W, Will Hand Schmitz ML (2002) Regulation of p53 activity by its interaction with homeodomaininteracting protein kinase-2. Nat. Cell. Biol. 4: 1-10. 